\title{
PFPRINT

\section{5) Plataforma online para diagnóstico diferencial das demências}

Aline Laginestra e Silva'; Gustavo de Azevedo Carvalho²; Karla Helena Coelho Vilaça e Silva²

\section{Resumo}

Introdução: O envelhecimento acelerado da população brasileira predispôs a condições mórbidas. Destacamos afecções mentais, sendo segunda causa de aumento de tempo de internação no Distrito Federal. Assim, avaliação fidedigna dos subtipos de demência dará subsídios para melhor abordagem, prevenção e tratamento destas condições. A associação de múltiplos testes, manifestações clínicas, biomarcadores e neuroimagem, permitirá que diagnóstico preciso seja realizado, sobretudo na Demência de Alzheimer. O desenvolvimento de uma plataforma de fácil acesso, disponível online, agregando todos os critérios diagnósticos, segundo protocolos validados, norteando indicação de marcadores biológicos estruturais e genéticos das doenças, representará ferramenta importante para uso profissional e institucional. Objetivo: Elaborar plataforma online que auxilie no diagnóstico das demências para uso profissional e institucional, além de colaborar com a construção de banco de dados epidemiológicos. Metodologia: Design Instrucional Sistemático. Equipe desenvolvedora composta por médico, desenvolvedor de software e designer. População alvo: profissionais de saúde e intuições de atendimento em saúde público e privado. Desenvolvimento: linguagem com HTML/HTML5, estruturação e marcação de conteúdo com folhas de estilo CSS/CSS3, layout e apresentação do documento com framework PhoneGap, acesso multiplataforma compatível com qualquer sistema. Fases de elaboração: algoritmos para detalhamento e avaliação de déficits cognitivos; para critérios diagnósticos específicos; para testes neuropsicológicos; para exames de bioquímica; para estudo genético; para achados neuropatológicos; link direto ao final do fluxo enviando diagnóstico de probabilidade ou definitivo para determinada demência com instituições de saúde, formando banco de dados. Resultados esperados: plataforma online acessível a profissionais de saúde e instituições, possibilitando o auxílio no diagnóstico de diferentes demências, com banco de dados, análise epidemiológica e mapeamento destes transtornos nas áreas estudadas. Considerações finais: trata-se de algo inovador, pois não existem bancos de dados epidemiológicos de demências no Brasil, essa plataforma reunirá elementos necessários para tal.

Palavras-chave: Demência; Epidemiologia; Alzheimer.

1 Mestranda no Programa de Pós-Graduação em Gerontologia da Universidade Católica de Brasília. Endereço para correspondência: QS 07 Lote 01 - EPCT - 71966-700 - Águas Claras - Taguatinga - DF. Email: alinelaginestra@gmail. com

2 Professores do Programa de Pós-Graduação em Gerontologia da Universidade Católica de Brasília. Endereço para correspondência: QS 07 Lote 01 - EPCT - 71966-700 - Águas Claras - Taguatinga - DF. Emails (na ordem em que aparecem): carvalhobsb@hotmail.com; kavilaca@yahoo.com.br 


\section{Introdução}

O envelhecimento acelerado da população brasileira predispôs a condições mórbidas. Destacamos afecções mentais, sendo segunda causa de aumento de tempo de internação no Distrito Federal. Assim, avaliação fidedigna dos subtipos de demência dará subsídios para melhor abordagem, prevenção e tratamento destas condições. A associação de múltiplos testes, manifestações clínicas, biomarcadores e neuroimagem, permitirá que diagnóstico preciso seja realizado, sobretudo na Demência de Alzheimer. O desenvolvimento de uma plataforma de fácil acesso, disponível online, agregando todos os critérios diagnósticos, segundo protocolos validados, norteando indicação de marcadores biológicos estruturais e genéticos das doenças, representará ferramenta importante para uso profissional e institucional.

\section{Objetivo}

Elaborar plataforma online que auxilie no diagnóstico das demências para uso profissional e institucional, além de colaborar com a construção de banco de dados epidemiológicos.

\section{Metodologia}

Design Instrucional Sistemático. Equipe desenvolvedora composta por médico, desenvolvedor de software e designer. População alvo: profissionais de saúde e intuições de atendimento em saúde público e privado. Desenvolvimento: linguagem com HTML/HTML5, estruturação e marcação de conteúdo com folhas de estilo CSS/CSS3, layout e apresentação do documento com framework PhoneGap, acesso multiplataforma compatível com qualquer sistema. Fases de elaboração: algoritmos para detalhamento e avaliação de déficits cognitivos; para critérios diagnósticos específicos; para testes neuropsicológicos; para exames de bioquímica; para estudo genético; para achados neuropatológicos; link direto ao final do fluxo enviando diagnóstico de probabilidade ou definitivo para determinada demência com instituições de saúde, formando banco de dados.

\section{Resultados esperados}

Plataforma online acessível a profissionais de saúde e instituições, possibilitando o auxílio no diagnóstico de diferentes demências, com banco de dados, análise epidemiológica e mapeamento destes transtornos nas áreas estudadas. 


\section{Considerações finais}

Trata-se de algo inovador, pois não existem bancos de dados epidemiológicos de demências no Brasil, essa plataforma reunirá elementos necessários para tal.

\section{Online platform for differential diagnosis of dementias}

Keywords: Dementia; Epidemiology; Alzheimer's disease. 